\title{
Neurology and Covid-19: Present and Future
}

\author{
Hernández Ramos, F J, ${ }^{1}$, PhD, MD, Hernández Chamorro, F J, ${ }^{2}$; Palomino García, A ${ }^{1}$; \\ Jiménez Hernández ${ }^{1}$, MD \\ ${ }^{1}$ Clinical Unit of Neurology and Neurophysiology, University Hospital "Virgen del Rocío". Sevilla University, \\ Sevilla, Spain \\ ${ }^{2}$ School of Medicine, Sevilla University, Sevilla (España)
}

Corresponding author: Dr Hernández Ramos, F J, PhD, MD; currohernandez@gmail.com; francisco.hernandez.ramos.sspa@juntadeandalucia.es

\begin{abstract}
We're witnessing a pandemic due to COVID-19, which has generated a strong impact in Public Health, Health Services and a economic level, still to be determinated. It's a recently discovered respiratory virus that has the capacity to produce neurological symptoms, either indirectly o directly. Much has been written about neurological symptoms, mainly by no-neurologist, and the frecuency and type of neurological manifestations must be precisely defined in both, acute and medium-long term phases. After carrying out and extensive bibliographic review, the objective of this paper is to analyze what has been described so far and how it can be improved to know exactly the type and frecuency of neurological manifestations related to COVID-19.
\end{abstract}

Keywords: Covid-19; SARS-Cov-2; neurological manifestations; pandemic; neurotropism; neurological disorders.

\section{Introduction}

Back in 1896, Sir William Osler said that humankind is facing three major problems: fever, famine and warfare, being fever the worst of them. Nowadays, we find ourselves fighting against a pandemic that has directly threatened Public Health, Sanitary Services and Economy. Causing a vast amount of infections and deaths, as well the need to develop several measurements such as social distancing or confinement, always seeking the common good. Something similar took place at the end of the Great War: the 1918 flu pandemic, wrongly named "the Spanish Flu", from which there are almost no survivors left.

Our current pandemic started at the end of 2019 in Wuhan, China ${ }^{[1]}$, rapidly acquiring the epidemic status and, short after, the pandemic one. It affected the areas of China, Southern Europespecially Italy and Spain-, U.S.A., and Latin America, with a special virulence. Few are the places which escape this virus' grip. To this day, 1st of June 2020, the number of infected rises to 6.171.341, with 372.166 deaths and 2.642.568 recoveries.

A beta-coronavirus is responsible for this pandemic. It was unknown until the recent events and it was named Covid-19 (SARS-Cov-2), encapsulated RNA virus, with a molecular mass that oscillates between 20-32 KB, genetic diversity and with the ability of carrying out recombination and thus, causing crossspecies transmission. It presents a high contagiousness index ${ }^{[2]}$, higher than the flu's and the one of the SARS-Cov-1. However, the current virus is less lethal than the last one. The virus is transmitted through airways, within 1 to 2 meters, and its survival improves in closed spaces, where aerosols can be created, and it can survive in fomites for 72 hours. It has been isolated in saliva, pulmonary secretions, urine and, rarely, in cerebrospinal fluid. Several asymptomatic patients are produced, and only a small percentage of them develops the disease, being olders the ones at a higher risk ${ }^{[3]}$. The disease is divided in three stages, I or initial, II, with respiratory issues, and III, which is related with the cytokine storm; the ability of producing neurological manifestations along three stages.

The pathogenic mechanism by which the disease can reach the nervous system is being studied. Recent studies point to haematogenous dissemination and through the olfactive bulb, where receptor ACE-2 ${ }^{[4-5]}$ and retrograde transsynaptic transport ${ }^{[6]}$ play an important role. As well as this, there's anecdotal evidence of neurotropism ${ }^{[7]}$ caused by the virus. That determinates the cytokine release syndrome ${ }^{[8]}$, that tends to be produced in stage III of the disease, to alter the blood-brain barrier's permeability, allowing the flow of molecules and cells, causing immune response at the nervous system's level and start inflammatory and immune mechanisms that can be responsible for neurological disorders ${ }^{[9]}$ and later manifestations (figure 1). 
COVID-19

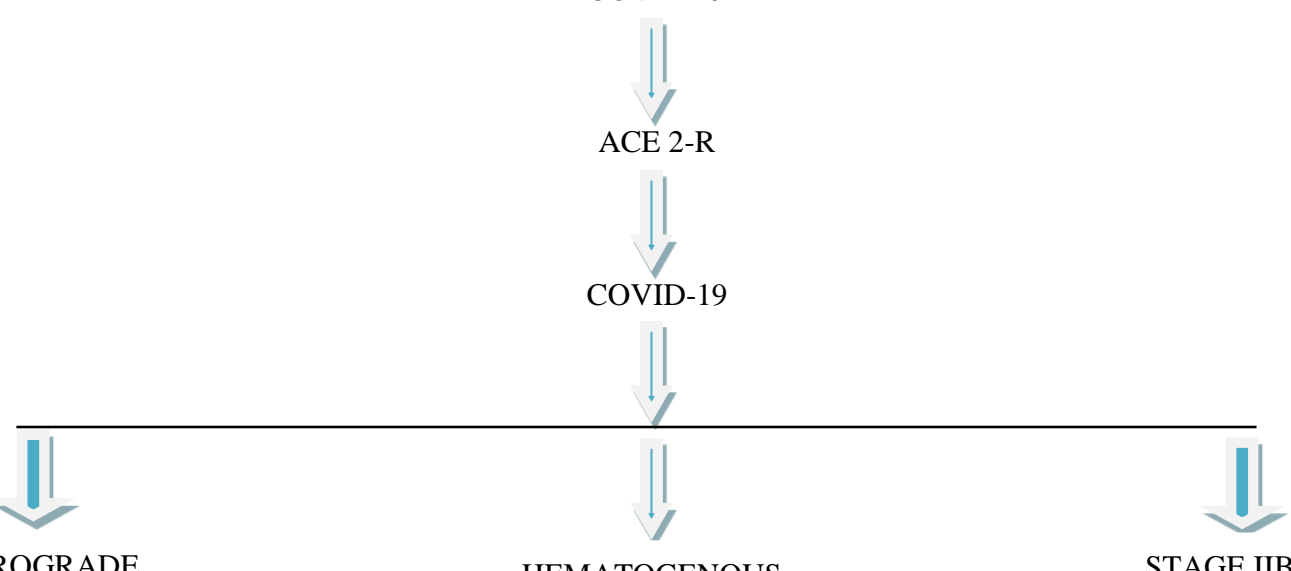

RETROGRADE

HEMATOGENOUS

STAGE IIB-III

\section{TRANSINAPTIC}
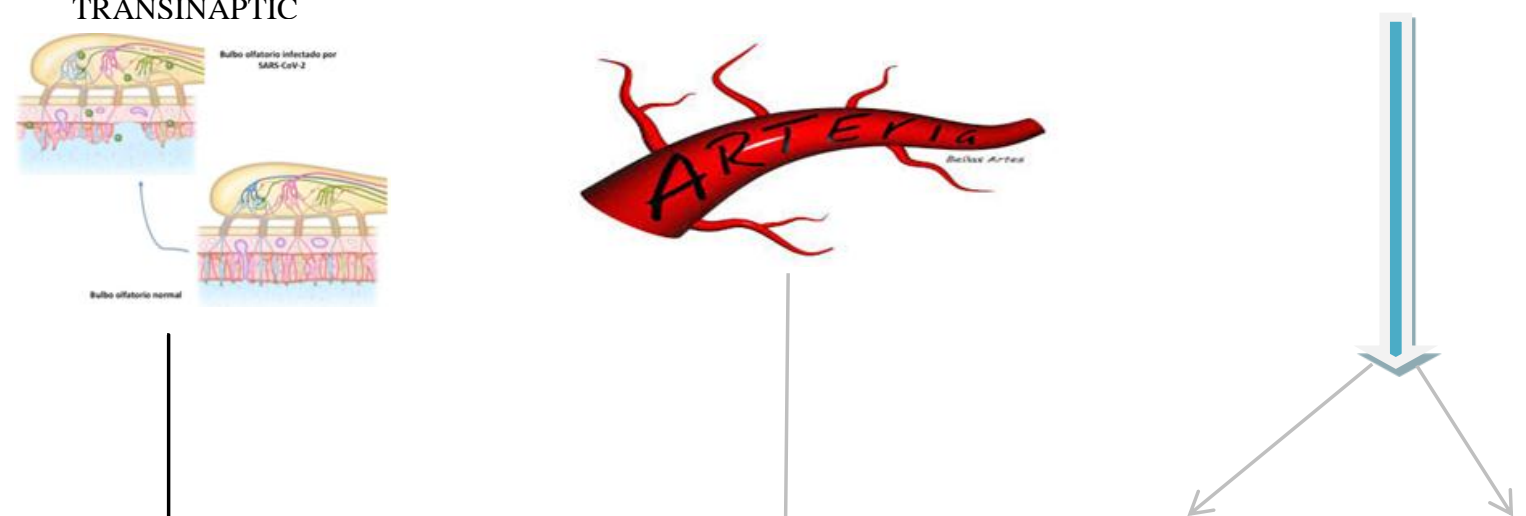

CYTOKINES STORM HYPOXIA

BLOOD BRAIN BARRIER
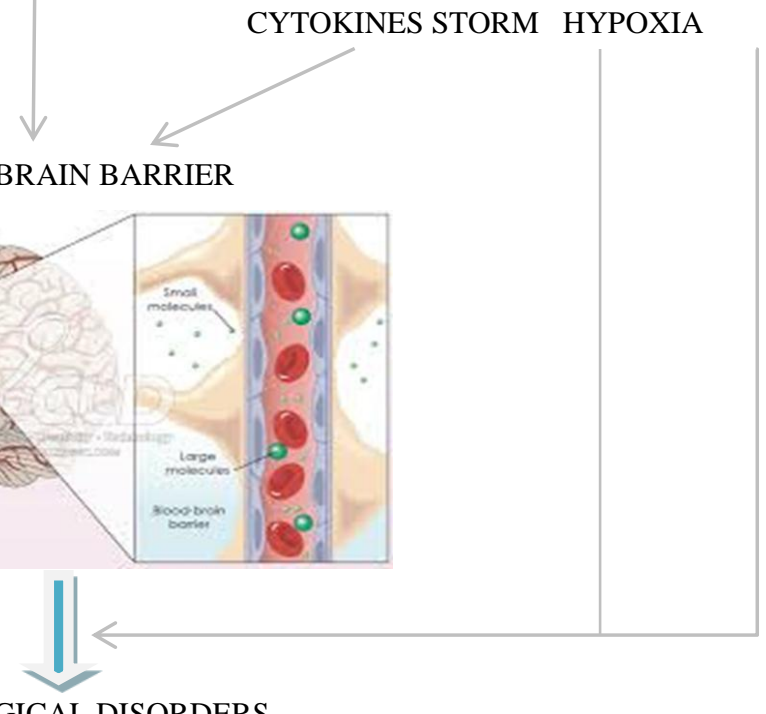

NEUROLOGICAL DISORDERS

ACE $2-\mathrm{R} \longrightarrow$ ANGIOTENSIN-CONVERTING-ENZIME RECEPTOR 2.

Figure 1: Pathophysiology of the neurological disorders due to covid-19. 


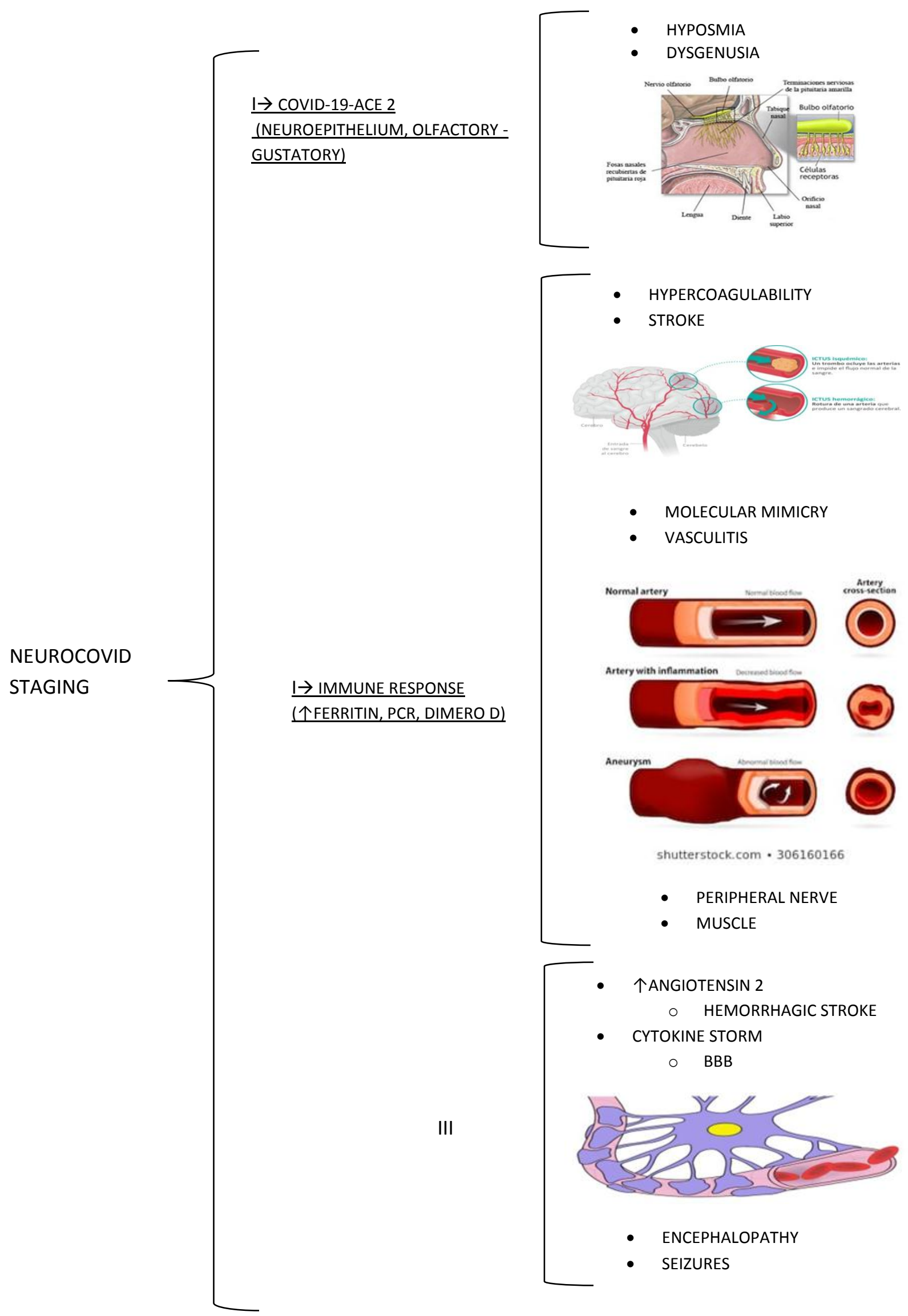

Figure 2

Few diseases have generated this high number of publications and in such a short period of time, regarding neurological manifestations. Covid-19 has the properties of neuroinvasion (penetrate the nervous system), neurotropism (affect glial cells and neurons) and neurovirulence (produce a neurological pathology). It is based on several criteria, including: biological plausibility, 
neurological damage that it can produce in other species, animal models of nervous system's invasion and neurological complications by other coronaviruses that Covid-19 patients have developed ${ }^{[10]}$. There are general series that define those manifestations. However, few of them have been done by neurologists.

Our main goal is to carry out a bibliographic review of those manifestations, allowing us to catalogue and define with a better accuracy the Covid-19 related neurological manifestations.

\section{Material and Methods}

In order to carry out our project, we have done a bibliographic research, using only those English-written articles from November 2019 to 2020 which are the most representative ones, for our analysis, and describe with the best quality the neurological manifestations caused by infection of beta-coronavirus Covid- 19 .

The following search is free for investigators and scientists and does not entail any kind of violation of patients' confidentiality.

\section{Result and Discussion}

We will now analyse the neurological manifestations described in literature related to Covid-19.

The article of Ling Mao et al. about unspecific symptoms, was published in JAMA Neurol ${ }^{[11]}$. They study the clinic manifestations and the neurological ones among them of 214 patients hospitalised in Wuhan. Above all, it was established that the most common neurological manifestations, that appear in the first stages of the disease and whose gravity increases throughout the infection, were: dizziness (36 cases), headache (23 cases), dysgeusia (12 cases) and hyposmia (5 cases). Subsequently, Guan et al. in NEJM ${ }^{[12]}$, analyse the clinical characteristics of 1099 patients hospitalised in Wuhan, describing that the $13.6 \%$ suffer from headaches and $15 \%$ from myalgia.

Hyposmia and dysgeusia are analysed in a multicentric hospital register of 12 European hospitals, with a total of 417 patients, by Leichen et al. ${ }^{[13]}$. Hyposmia is present in $85 \%$ of the patients, and dysgeusia in $88 \%$. Those manifestations can even be found in the absence of nasal symptoms and appear suddenly, with a higher frequency in the minor stages because it is more difficult to test them in the final ones. As well as this, it is said that they could be a sign of the disease ${ }^{[14]}$.

Encephalopathy- fluctuating, reversible and global cerebral dysfunction- is more common between older patients, along with hypertension and other comorbidities, primarily obesity and with previous cognitive decline. They look like a vulnerable group, as well as those who take ECA suppressors. In Mao's study, a 15\% of severe Covid-19 patients, underwent consciousness' alterations. Fitalov publishes ${ }^{[15]}$ that encephalopathy's origin is multifactorial, including toxic-metabolic causes, focusing on hypoxia, neurotoxic side effects of drugs and subclinical seizures.

Moniguchi et al. ${ }^{[16]}$ publish the first case of encephalitis linked with Covid-19, in a Japanese patient with inflamed cerebrospinal fluid and positive RCP. This is the first case where a direct threat to the nervous system by the virus is observed. A case of Covid-19 associated acute haemorrhagic necrotizing encephalopathy is described by Poyiadji et al. ${ }^{[17]}$, in a radiology journal. The disease is confirmed by nasopharynx RCP and injuries at bilateral anterior temporal, thalamus and insula levels are observed. The previous manifestations are related with the cytokine release syndrome. In both above described cases, even though they are anecdotical, a certain predisposition to produce limbic encephalitis is appreciated. Myelitis ${ }^{[18]}$ is thought to have a connection with Covid-19.

Thromboembolic manifestations, specifically stroke ${ }^{[19]}$, have been described with the disease, being more frequent in the late stages of it and seem to share a connection with D-dimer, hypercoagulability, cytokine release syndrome and the infection's gravity. Five cases of young patients with large vessel stroke in New York, with no vascular risk factors history, are published in NEJM ${ }^{[20]}$. Moreover, Barrios-López et al ${ }^{[21]}$ describe four stroke cases in severe Covid-19 infected patients. Mao's description, with 214 hospitalised patients, several neurological manifestations are described: ischemic strokes, one haemorrhagic stroke and cerebral venous thrombosis.

Regarding peripheral nervous system's manifestations, Sedaghat and Toscano ${ }^{[22-23]}$ describe Guillain-Barré's syndrome, which occurs two weeks after the initial stage of the infection. They found evidence of demyelination in the electromyography, suggesting an immune-mediated origin. In addition, GutiérrezOrtiz et al ${ }^{[24]}$ describe two cases of cranial polyneuritis, compatible with Miller-Fisher's syndrome, two weeks after infection. Muscle affection seems to be a common manifestation in the early stages of the disease, and tend to increase as the illness degenerates. Cases of rhabdomyolysis have been described ${ }^{[25]}$.

In relation to the medium to long term neurological manifestations, Serrano Castro et al. ${ }^{[26]}$ state in their article, the possibility of producing an immune/inflammatory phenomenon on vulnerable patients with a neurodegenerative and psychiatric pathology that modifies those diseases' normal course.

ALBACOVID register's data, published in Neurology, by Romero-Sánchez et al. ${ }^{[27]}$ is the first hospital record in which the neurological manifestations are described by neurologists from two Spanish hospitals. It is a retrospective and hospital study with 814 positive Covid-19 patients, where the $50.4 \%$ develop neurological manifestations. The average age of the sample is 66.4 years, with $56 \%$ males. They develop myalgias $(17.2 \%)$, cephalea (14.1\%), dizziness (6.1\%), dysgeusia (6.2\%) and hyposmia (4.9\%). Consciousness' level manifestations happen in a $19.6 \%$ of the patients, being more frequent in the graver and older ones. Myopathy (6.1\%), dysautonomia (2.5\%), stroke (1.7\%), seizures and movement disorders $(0.7 \%)$, one case of encephalitis, GuillainBarre syndrome and optic neuropathy. Neurological manifestations were related with the $4.2 \%$ of deaths. The authors suggest that in order to analyse the neurological manifestations due to Covid-19 infection, there must be a separation between the following levels: unspecific neurological symptoms (dizziness, headache and myalgia), neuro-psychiatric alterations (anxiety, insomnia, depression and psychosis), central nervous system's alterations (direct viral infection, consciousness' level alterations, stroke and seizures), peripherical nervous system's alterations (cranial and peripherical neuropathies), myopathy and demyelinating disease.

We are currently facing an increase in available literature about the nervous system's damage, caused by Covid-19 infection. Nevertheless, few of them are written by neurologists ${ }^{[28]}$ and virtually none are a population study that analyses the neurological manifestations in a global manner. It is important to define which are the essential mechanisms of that affectation. The cytokine release syndrome appears to play an important role, contributing to increasing the blood-brain barrier's permeability, causing molecules and cells to flow into the nervous system. Hypoxia is also important, as well as the direct injury mechanism by the virus, like HIV- from which we have anecdotical data. It can reach the nervous system through the blood vessels, using the "Trojan's 
horse" mechanism. This event's likelihood increases with the cytokine storm, in the gravest scenarios of the disease. Furthermore, the retrograde transsynaptic transport through the olfactory bulb is also an essential mechanism. There is an report, where the IRM signal seems to intensify in the frontobasal lobe and fade with Covid-19 recovery ${ }^{[29]}$. Respiratory system's chemoreceptors/mecanoreceptors can influence in the Covid-19 related type 2 respiratory failure, where the ACE2 receptors play an important role. A recent neuropathologic study with 18 Covid19 patients ${ }^{[30]}$, shows that the primal changes are caused by hypoxia and that there are no viral particles in those brains. As a result, hypoxia and cytokine storm acquire a lead role in this disease's neurological manifestations.

Recently, "NeuroCovid Staging" ${ }^{[31]}$ is being used as a better way of understanding physiopathology and the neurological manifestations produced (Table 1).

- $\quad$ Stage I. The virus unites the ACE2 in the olfactory and gustatory neuroepithelia. Cytokine storm is mild. Symptoms are dysgeusia and hyposmia.

- $\quad$ Stage II. A strong immune response is produced, with a ferritin, reactive $\mathrm{C}$ protein and $\mathrm{D}$ dimer increase. That leads to, on one hand, a hypercoagulability that provokes strokes, and on the other hand, an immune response and vasculitis. As a result, there is damage on the cranial nerves, peripheral nerve and muscles.

- $\quad$ Stage III. The cytokine storm damages the blood-brain barrier, favouring molecules and cells flow, as well as the virus. Consequently, there is brain damage and edema, leading to encephalopathy and seizures. An increased level of angiotensin favours hypertension and brain haemorrhage.

Just like it was observed in the 1918 Flu Pandemic, regarding Von Economo's encephalitis; and currently, with the HIV-related cognitive impairment- that even though it has zero viral blood presence, it causes an inflammatory response, maintained by HIV, in the nervous system- it is necessary to define the medium to long term neurological manifestations present in a specially vulnerable population, such as those with neurodegenerative diseases caused by Covid-19. The SARS-Cov1 epidemic favoured Parkinson's disease and multiple sclerosis development ${ }^{[32-33]}$. The high ACE-2 content in the neurons and the glial cells can determine its influence on developing medium to long term neurodegenerative and age-related diseases. Therefore, evidence shows the importance of neurologists monitoring Covid-19 patients.

Table 1: Shows the Covid-19 related neurological manifestations described in literature.

\begin{tabular}{|c|c|}
\hline $\begin{array}{l}\text { GENERAL } \\
\text { SYMPTOMS }\end{array}$ & $\begin{array}{ll}\text { - } & \text { DIZZINESS } \\
\text { - } & \text { HEADACHE } \\
\text { - } & \text { ASTHENIA }\end{array}$ \\
\hline $\begin{array}{l}\text { CENTRAL } \\
\text { NERVOUS SYSTEM }\end{array}$ & $\begin{array}{ll}- & \text { ENCEPHALOPATHY } \\
\text { - } & \text { ENCEPHALITIS } \\
\text { - } & \text { ACUTE HAEMORRAGIC NECROTIZING ENCEPHALOPATHY } \\
\text { - } & \text { MYELITIS } \\
- & \text { EPILEPTIC SEIZURES } \\
- & \text { STROKE (ISCHEMIC, HAEMORRHAGIC, BRAIN VENOUS THROMBOSIS) } \\
\text { - } & \text { ATAXIA } \\
\text { - } & \text { DISORDERS OF MOVEMENT } \\
- & \text { NEUROPSYCHIATRIC (ANXIETY, INSOMNIA, DEPRESSION AND PSYCHOSIS) }\end{array}$ \\
\hline $\begin{array}{l}\text { PERIPHERAL } \\
\text { NERVOUS SYSTEM }\end{array}$ & $\begin{array}{ll}\text { - } & \text { HYPOSMIA } \\
\text { - } & \text { DYSGENUSIA } \\
\text { - } & \text { OPTIC NEURITIS } \\
\text { - } & \text { CRANIAL POLYNEUROPATHY (MILLER-FISHER) } \\
\text { - } & \text { GUILLAIN BARRE SYNDROME } \\
\text { - } & \text { DISAUTONOMY } \\
\text { - } & \text { NEUROPATHIC PAIN } \\
\text { - } & \text { MYALGIAS } \\
\text { - } & \text { RABDOMYOLYSIS }\end{array}$ \\
\hline
\end{tabular}

This pandemic has caused a reorganisation in the Sanitary Services- as a whole- and in the Neurology Services-in particular [34-35].

Finally, we can conclude the following about the Covid-19 related neurological manifestations:

- Covid-19 related neurological manifestations and their frequency are still a subject of study.

- The most common neurological manifestations are cephalea, dizziness and myalgia.

- Anosmia might be an indicator of the disease.

- Encephalopathy, stroke and seizures are becoming more frequent. They are all related to the cytokine storm, where hypoxia acquires a critical role. Encephalopathy is the most frequent one. This has been observed in 18 autopsied patients.

- Encephalitis and polyradiculopathy are infrequent. A certain level of tropism could cause limbic encephalitis, due to the increase in the temporal hematoencephalic barrier's fragility.

"Neurocovid Staging" seems to be very adequate for having a better understanding of physiopathology and neurological manifestations.

- It is necessary to increase the amount of secondary Covid-19 related neurological manifestations registers, conducted by neurologists, in the acute phase and in a medium to long term range, because of the likely neurological manifestations. 
- Likewise, it is necessary to increase the number of population studies in order to have a global view of the virus-related neurological manifestations.

It might be a priority to increase the number of pathological autopsies, in order to get to know the essential mechanisms that cause the Covid-19 related neurological pathologies.

\section{Appreciation}

To Loli Chamorro Jiménez and Paula Hernández Chamorro, for their help when it came to write this article.

\section{Ethics approval and consent to participate}

Not applicable.

\section{List of abbreviations}

RNA: Ribonucleic acid.

KB: Kilobases.

ACE: Angiotensin converting enzyme.

BBB: Blood-brain barrier.

RCP: Polymerase chain reaction.

HIV: Human immunodeficiency virus.

IRM: Nuclear magnetic resonance.

\section{Conflicts of Interest}

"The author(s) declare(s) that there is no conflict of interest regarding the publication of this paper."

\section{Funding Statement}

Not applicable.

\section{Authors' contributions}

Hernández Chamorro FJ, Palomino García A and Jiménez Hernández MD, have helped in the bibliographic review and in the final preparation of this paper and was a major contributor in writing the manuscript. All authors read and approved the final manuscript."

\section{Acknowledgments}

To Loli Chamorro Jimenez and Paula Hernández Chamorro for their help in the figures and table and traduction of this paper.

\section{Bibliography}

[1] Zhu N, Zhang D, Wang W, et al. A novel coronavirus from patients with pneumonia in China, 2019. N Engl J Med 2020; 382: 727-32.

[2] Chan JF, Yuan F, Kok K, et al. A familial cluster of pneumonia associated with the 2019 novel coronavirus indicating person-to-person transmission: a study of familial cluster. Lancet 2020; 395: 514-23.

[3] Ministry of Health, Labour and Welfare. Official report on the cruise ship Diadmon Princess. March 5 2020, (https://www.mhlw.go.jp/stf/newpage_09997.htlm).
[4] Hoffmann M, Klainer-Weber H, Schoroeder S, et al. SARS-Cov-2 cells entry depends on ACE2 and TMPRSS 2 and is blocked by a clinically proven protease inhibitor. Cell.2020; 18(2): 271-280.e8. doi:10.1016/j.cell.2020.02.052.

[5] Chen R, Wang K, Yu J, Chen Z, Wen C, Zu Z. The spatial and cell-type distribution of SARS-Cov-2 receptor ACE2 in human and mouse brain. Published Abril 9, 2020. Accessed May 18, 2020. https://www.biorxiv.org/content/10.1101/2020.04/07.030 650vl.

[6] Li YC, Bai WZ, Hirano N, et al. Neurotropic virus tracing suggest a membranous-coating-mediated mechanism for trassynaptic communication. J Comp Neurol.2013;521(1): 203-212.doi:10.1002/cne.23171

[7] Li Y-X, Bai WZ, Hashikawa T. The neuroinvasive potencial of SARS-Cov-2 may be at least partially responsible for the respiratory failure of COVID-19 patients. J Med Virol.Published on line February 26.2020.doi:10.1002/jmv.25728.

[8] Mehta P, McAuley DF, Brown M, Sánchez E, Tattersall RS, Manson JJ; HLH Across Speciality Colaboration, UK COVID-19: consider cytokines storm syndromes and inmunosupression. Lancet 2020;395(10229):10331034.doi:10.1016/S0140-6736(20)30628-0.

[9] Sankwoski R, Mader S, Valdés-Ferrer SI. Systemic inflammation and the brain: novel roles of genetic, molecular and envorovimental cues as drivers of neurodegeneration. Front Cell Neurosci 2015.; 9(28):28.doi:10.3389/fncel.2015.00028

[10] Carod-Artal Francisco J. Complicaciones neurológicas por coronavirus y COVID-19. Rev Neurol 2020; 70 (9): 311-322.

[11] Ling Mao, HIjuan Jin, Mengdie Wang, et al. Neurological manifestations of hospitalizated patients with coronavirus disease 2019 in wuhan, China. JAMA Neurol.2020; 77(6):683690.doi:10.1001/jamaneurol.2020.1127.

[12] Guan W, Ni Z, Hu Y, et al. Clinical characteristics of coronavirus disease 2019 in China. N Eng J Med 2020;382: 1708-1720.doi:10-1056/NEJMoa2002032.

[13] Leichen J, Chiesa-Estomba CM, De Siati Dr, et al. Olfactory and gustatory dysfunctions as a clinical presentations of mild-to-moderate forms of the Coronavirus disease (COVID-19): A multicenter European Study. Eur Arch Otorhinolaringol.2020 Apr 6; 1-11.doi: 10.1007/s00405-020-05965-1.

[14] Vaira LA, Salzano G, Deiana G, De Riu G. Anosmia and agenusia:common findings in Covid-19 patients. Laryngoscope 2020.doi:10.1002/lary.28692.

[15] Filatov A, Sharma P, Hindi F, Espinosa P. Neurological complications of Coronavirus disease (COVID-19): Encephalopathy. Cureus 2020 March 21.12 (3):e7352. doi:10.7759/cureus.7352.

[16] Moriguchi T, Harii N, Goto J, et al. A first case of meningitis/encephalitis associated with SARScoronavirus-2. Int J Infect Dis.2020;94:55-58.doi:101016/j.ijid.2020.03.062.

[17] Poyiadji N, Shajin G, Noujaim D, Stone M, Patel S, Griffith B. COVID-19 associated acute haemorragic necrotizing encephalophaty: CT and MRI features. Radiology. Published on line April 6, 2020. doi:/10.1148/radiol.2020201187. 
[18] Zhao K, Huang J, Dai D, Feng Y, Liu L, NIe S. Acute myelitis after SARS-Cov-2 infection: a case report. Published March 18, 2020.Accesed May 19, 2020. https://medrxiv.org/content/10.1101/2020.03.16.2003510 $5 \mathrm{v} 2$

[19] Li Y, Wang M, Zhou Y, et al. Acute cerebrovascular disease following COVID-19: a single center, retrospective, observational study. SSRN Electronic Journal. Published on line April 2020. doi: 10.2139/ssrn.3550025.

[20] Oxley TJ, Mocco J, Maijidi S, et al. Large-vessel stroke as a presenting feature of COVID-19 in the young. N Eng J Med 2020: 382(20); e60. doi:10.1056/NEJMe2009787.

[21] Barrios-López JM, Rego-García I, Muñoz Martínez C, et al. Ischaemic stroke and SARS-Cov-2 infection: A causal or incidental association. Neurologia.2020. https://doi.org/10.1016/j.nrl.2020.05.002

[22] Sedaghat Z, Karimi N. Guillain-Barré syndrome associated with COVID-19 infecction: a case report. J Clin Neurosci.2020:SO967-5868(20)30882-1.

[23] Toscano G, Palmerini F, Ravaglia S, et al. Guillain-Barre syndrome associated with SARS-Cov-2. N Engl J Med, 2020. Doi:10.1056/NEJMe2009191

[24] Gutiérrez-Ortiz C, Méndez A, Rodrigo-Rey S, et al. Miller-Fisher syndrome and polineuritis cranialis in COVID-19. Neurology. Published on line April 17, 2020. Doi:10.1212/WNL.00000000000009619

[25] Guidon AC, Amato AA. COVID-19 and neuromuscular disorders.Neurology 2020. doi:10.1212/WFNL0000000000009566

[26] Serrano Castro PJ, Estivil Torrús G, Cabezudo García P, et al. Impact of SARS-Cov-2 infection on neurodegenerative and neuropsychiatric diseases: a delayed pandemic. Neurología (English edition), volume 35, Issue 4, May 2020, pages 245-251.

[27] Romero Sánchez CM, Díaz Maroto I, Fernández Díaz E, et al. Neurologic manifestations in hospitalized patients with covid-19. The ALBACOVID registry. Neurology,2020. Published ahead of print on June 1, 2020 as $10.1212 /$ WNL0000000000009937

[28] Helms J, Kremer S, Merdji H, et al. Neurologic features in Severe SARS-Cov-2 infection. Letter to the Editor. N Engl J Med, 2020. doi:10.1056/NEJMc2008597

[29] Politi LS, Salsano E, Grimaldi M. Magnetic Resonance Imaging alteration of the brain in a patient with Coronavirus disease (Covid-19) and anosmia. JAMA Neurol, 2020. Published on line: May 29, 2020. Doi:10.1001/jamaneurol.2020.2125

[30] Solomon IH, Normandin E, Bhattacharyya S, et al. Neurophatological features of Covid-19. Letter to Editor. N Engl J Med, 2020. doi: 10.1056/NEJMc2019373

[31] Fotuhi M, Mian A, Meysamy S, Raji CA. Neurobiology of COVID-19. Journal of Alzheimer's disease, 2020. doi:10.3233/JAD-200581

[32] Fazzini E, Fleming J, Fahn S. Cerebrospinal fluid antibodies to coronavirus in patients with Parkinson's disease. Mov Disord 1992, vol 7, 153-8.

[33] Murray RS, Cai GY, Hoel K, Johnson S, Cabirac GF. Coranavirus and multiple sclerosis. Adv Exp Med Biol 1993, 342, 353-357.

[34] Matías-Guiu J, Matías-Guiu JA, Álvarez-Sabinj, et al.Will neurological care change over the next 5 years due to the COVID-19 pandemic?. Key informant consensus survey. Neurologia (English edition), Volume 35, issue 4, Pages 252-257. https://doi.org/10.1016/j.nrl.2020.04.006

[35] Hernández Ramos FJ, Palomino García A, Jiménez Hernández MD. Neurology during the pandemic. Is COVID-19 changing the organisation of neurology departments. Neurologia (English edition), Volume 35, issue 4, Pages 269-271. https://doi.org/10.1016/j.nrl.2020.04.009 